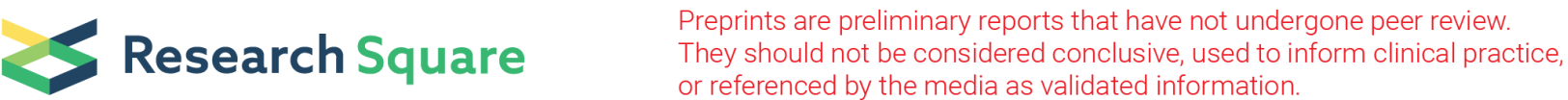

\section{The relationship between collagen proportionate area and Hepatitis B surface antigen levels in e antigen positive hepatitis $B$ cirrhosis}

Rui Yu

Zhengzhou University First Affiliated Hospital

Qiangwei Shi ( $\square$ shiqiangwei2007@126.com )

Zhengzhou University First Affiliated Hospital https://orcid.org/0000-0002-7026-8104

Qian Sun

Zhengzhou University First Affiliated Hospital

Chunfeng Wang

Zhengzhou University First Affiliated Hospital

Jianning Yao

Zhengzhou University First Affiliated Hospital

Lianfeng Zhang

Zhengzhou University First Affiliated Hospital

Research article

Keywords: HBsAg, liver fibrosis, collagen proportionate area, chronic hepatitis B

Posted Date: December 15th, 2019

DOI: https://doi.org/10.21203/rs.2.18968/v1

License: () (1) This work is licensed under a Creative Commons Attribution 4.0 International License.

Read Full License 


\section{Abstract}

Background: Quantitative serum HBsAg has been widely used as a biomarker for treatment response and prognosis in chronic hepatitis $B$, and recently been found associated with liver histology in HBeAg positive patients. Collagen proportionate area (CPA) as a continuous variable is a appropriate histological measurement to assess the degree of fibrosis and substages cirrhosis. We aimed to explore the association of serum HBsAg level with CPA in e antigen positive hepatitis B cirrhosis.

Methods: Liver fibrosis staging was evaluated semiquantitatively according to the Metavir scoring system, only patients with METAVIR stage 4 were included. All liver biopsies were restained with picroSirius red for collagen quantification and determination of CPA by digital image analysis.

Results: Mean collagen proportionate area value was $23.46 \%$. The percentage of patients with different classification of CPA $(<20 \%, 20 \%-30 \%,>30 \%)$ were $25.8 \%, 57.8 \%$, and $16.4 \%$, respectively. A modest correlation was observed between CPA and serum HBsAg $(r=-0.306, p=0.001)$. HBsAg level is independently associated with collagen proportionate area in multivariable linear regression analyses.

Conclusion: Serum HBsAg levels can predict liver fibrosis determined by CPA in e antigen positive hepatitis B cirrhosis.

\section{Introduction}

Detection of hepatitis B surface antigen (HBsAg) in the serum that identified hepatitis B virus (HBV)[1], was awarded the Nobel prize about 50 years ago. Until now the presence of HBsAg is generally considered diagnostic for HBV infection. Although quantification of HBsAg was introduced more than 30 years ago, only recently has it been significantly improved by new commercial automated quantitative assays that started the interest in quantitative serum HBsAg as a biomarker for treatment response and prognosis in chronic hepatitis B[2]. While serum HBsAg levels have been demonstrated to be clinically useful for monitoring of pegylated interferon alfa treatment and nucleos(t)ide analogue treatment[3], for identifying the stage of disease[ 4,5$]$, for distinguishing true inactive carriers from patients with hepatitis $B$ e antigen-negative disease[6, 7], there has studies focused on the clinical significance of serum HBsAg levels and association with liver histology in $\mathrm{HBeAg}$ positive chronic hepatitis $\mathrm{B}[8,9]$.

In a large cohort of chronic hepatitis B (CHB) patients, an association between lower serum levels of HBsAg and the presence of moderate to severe fibrosis (METAVIR stages F2-F4) was found in treatmentnaïve, e antigen-positive patients[8]. In another cohort from Hong Kong, among e antigen-positive patients with alanine aminotransferase (ALT) $\leq 2 \mathrm{ULN}$, high serum HBsAg levels can accurately predict fibrosis score $\leq 1$ (Ishak scoring system)[9]. However, the commonly used histological hepatitis scoring systems, use similar principles to describe the stage of the liver disease[10-12]. In all systems, histological stage scores comprises a mixture of features that mainly depend on architectural changes, without reference to 
the quantity, quality and distribution of collagen, which is the direct cause of liver fibrosis. The "number" in the stage score are not continuous variables and are not quantitatively related that cannot be used as a measurement. For example, METAVIR stage 4 does not equal to twice as much fibrosis as stage 2 . However, the two items have always been confused which led to misinterpretation of data in the literature. Furthermore, each of the descriptive morphological stages of chronic liver disease, especially for advanced liver disease, contains a wide range of quantitative values for fibrosis, a significant limitation of current morphological category is that it contains no sub-classification[13]. Thus, a histological technique that measures the amount of fibrosis properly in advanced-stage liver disease is of great interest in liver pathology. A measurement that fulfils these requirements is a computer-assisted digital image analysis (DIA) that directly quantitatively measures liver fibrosis, the histological sections that are stained by PicroSirius Red which identifies the tissue collagen primarily[14]. The quantity of bound stain correlates well with both chemically determined liver collagen content and morphometricallydetermined hepatic fibrosis[15]. DIA uses digital images segmentation technique to measure both the area of collagen and the tissue, calculating a proportion of collagen to tissue that defined as collagen proportionate area (CPA), which represent liver fibrosis degree more accurately than liver stage. In addition, the "cirrhosis" stage category has poor prognostic power, in Ishak stages 5 and 6, CPA correlated well with hepatic vein pressure gradient, but had a wider range of values, suggesting a greater sensitivity for distinguishing "early" from "late" cirrhosis, CPA as a continuous variable is a appropriate histological measurement to assess the degree of fibrosis in advanced-stage liver disease, thus effectively substages cirrhosis and improves the description of liver disease stage[16].

Currently, although there has studies focused on the clinical significance of serum HBsAg levels on liver histology, little is known about the association between HBsAg levels and CPA at any specific time point. In this retrospective, cross-sectional single centre study, we therefore aimed to discuss the relationship between HBsAg levels and liver fibrosis assessed by the amount of liver collagen by the picroSirius red stain in e antigen positive chronic Hepatitis B patients with liver cirrhosis, and to predict liver fibrosis by using serum HBsAg levels.

\section{Materials And Methods}

\section{Patients}

One hundred and twenty eight treatment-naïve HBeAg-positive CHB patients with liver biopsy approved cirrhosis between 2003 and 2015 were enrolled in the study. Liver biopsy was performed in all patients within 1 month before or after the serum tests. Inclusion criteria for the present study were chronic infection with $\mathrm{HBV}$, and defined as detectable hepatitis $B$ surface antigen (HBsAg) $\geq 6$ months, age $\geq 18$ years, treatment naive for both nucleos(t)ide analogs or interferon. Exclusion criteria were: (i) advanced liver cirrhosis (Child-Pugh score >6); (ii) presence of hepatocellular carcinoma or a-fetoprotein $\geq$ $50 \mathrm{ng} / \mathrm{mL}$; (iii) other causes of liver disease or mixed causes (excessive alcohol consumption, hepatitis $\mathrm{C}$, hepatitis $D$, autoimmune liver disease, Wilson disease, hemochromatosis); (iv) human immunodeficiency virus co-infection; and (v) malignant disease or severe chronic disease. Informed consent wasobtained 
from each patient included in the study. The study proto-col conformed to the ethical guidelines of the 1975 Declaration ofHelsinki (6th revision, 2008) as reflected in a prior approval by theinstitution's human research committee.

\section{Diagnostic tests}

HBsAg levels (expressed as $\log _{10} \mathrm{IU} / \mathrm{mL}$ ) were measured using the Elecsys ${ }^{\circledR}$ HBsAg II quant assay (Roche Diagnostics, Mannheim, Germany). Serum HBV DNA levels were measured using the cobas TaqMan ${ }^{\circledR}$ assay (Roche Diagnostics, Mannheim, Germany) and expressed as $\log _{10} \mathrm{IU} / \mathrm{ml}$, with a lower limit of detection $20 \mathrm{IU} / \mathrm{mL}$.

\section{Liver histology}

Liver specimens obtained from liver puncture were fixed in formalin, embedded in paraffin and sectioned at $3 \mu \mathrm{m}$ in thickness. One tissue section was stained with HE trichrome and another with Masson's trichrome stain, liver fibrosis staging was evaluated semiquantitatively according to the Metavir scoring system, only patients with METAVIR stage 4 were included in the study[10].

All liver biopsies were restained with picroSirius red for collagen quantification and determination of CPA by DIA which was performed by one author (Y.R.). After whole section digital image capture, CPA was measured with Image-Pro plus 6.0 software (Media Cybernetics Co., Ltd, Bethesda, MD, USA). The CPA measurement need eliminate structural collagen in large portal tracts (which do not represent diseaserelated collagen) and image artefacts, lymphoid aggregates and vascular cavities as unfilled natural spaces were aslo not included in the measurement. CPA is expressed as a proportion (\%) of collagen to tissue area.

\section{Statistical analysis}

Statistical analysis of the data was performed using the statistical package SPSS (version 19.0; SPSS, Inc., Chicago, IL, USA). Categorical variables are presented as frequencies (\%) and continuous variables are presented as the mean \pm SD. Levels of HBsAg and HBV-DNA were transferred to $\log _{10} \mathrm{IU} / \mathrm{mL}$. Chisquare was used for categorical variables. Mann-Whitney or Kruskal-Wallis test was used for similar comparison of nonparametric data. Correlation between variables was evaluated by Spearman correlation. Multivariable linear regression analysis was applied to determine the independent association between HBsAg level and CPA. Age and gender were adjusted in Model 2, further adjusted for PLT, bilirubin and HBV DNA in Model 3. A p value $<0.05$ was considered statistically significant.

\section{Results}

\section{Study population}

One hundred and twenty eight consecutive, treatment-naïve positive CHB patients with liver cirrhosis by METAVIR score were included in the study. There were 92 (72\%) males and $36(28 \%)$ females. Clinical and 
histological characteristics of the patients are given in Table 1.

Table 1

Demographic, clinical and histological features of 128 patients with liver cirrhosis

\begin{tabular}{|ll|}
\hline Factors & \\
\hline Patients $(\mathrm{n}, \%)$ & 128 \\
\hline Male/female & $92 / 36$ \\
\hline Age, years & $30.27 \pm 9.36$ \\
\hline ALT level, U/L & $229.90 \pm 209.20$ \\
\hline Platelets $\left(\times 10^{12} / \mathrm{L}\right)$ & $165.14 \pm 47.86$ \\
\hline WBCs $\left(\times 10^{9} / \mathrm{L}\right)$ & $5.66 \pm 1.76$ \\
\hline Hb (g/L) & $139.76 \pm 14.56$ \\
\hline Total Bilirubin (umol/L) & $21.20 \pm 17.94$ \\
\hline Albumin $(\mathrm{g} / \mathrm{L})$ & $39.58 \pm 4.20$ \\
\hline HBV DNA level, log $10 \mathrm{IU} / \mathrm{mL}$ & $6.63 \pm 1.08$ \\
\hline HBsAg level, log 10 IU/mL & $3.67 \pm 0.84$ \\
\hline CPA, \% & $23.46 \pm 6.66$ \\
\hline Data are shown as mean \pm standard deviation. & \\
\hline ALT, alanine aminotransferase; WBCs, white blood cells; Hb, haemoglobin; HBeAg, hepatitis B early \\
antigen; HBsAg, hepatitis B surface antigen; CPA, collagen proportionate area.
\end{tabular}

Average mean of CPA in the assessable cohort was $23.46 \pm 0.66 \% .25 .8 \%$ patients had CPA $<20 \%, 57.8 \%$ patients had CPA at $20 \%-30 \%, 16.4 \%$ had CPA $>30 \%$, respectively.

Characteristics of patients with different CPA stratification

We stratified the patients into three groups according to the above-defined cut-off values of CPA $(<20 \%$, $20-30 \%,>30 \%$, respectively), and their characteristics were compared. As shown in Table 2, patients with higher CPA group (>30\%) had significantly lower levels of 
Table 2

Characteristics of patients with different CPA stratification

\begin{tabular}{|c|c|c|c|c|}
\hline Factors & $<20 \%(n=33)$ & $\begin{array}{l}\text { CPA } \\
20 \%-30 \%(n=74)\end{array}$ & $>30 \%(n=21)$ & $P$ value \\
\hline Age & $30.67 \pm 10.62$ & $30.07 \pm 9.68$ & $30.33 \pm 5.69$ & 0.803 \\
\hline $\begin{array}{l}\text { Gender }(\%) \\
\text { Female } \\
\text { Male }\end{array}$ & $\begin{array}{l}36.4 \% \\
63.6 \%\end{array}$ & $\begin{array}{l}25.7 \% \\
74.3 \%\end{array}$ & $\begin{array}{l}23.8 \% \\
76.2 \%\end{array}$ & 0.467 \\
\hline $\mathrm{Hb}(\mathrm{g} / \mathrm{L})$ & $138.34 \pm 12.35$ & $140.92 \pm 15.58$ & $138.00 \pm 14.36$ & 0.432 \\
\hline WBC $\left(\times 10^{9} / \mathrm{L}\right)$ & $5.78 \pm 1.40$ & $5.67 \pm 1.88$ & $5.39 \pm 1.80$ & 0.474 \\
\hline $\operatorname{PLT}\left(\times 10^{12} / \mathrm{L}\right)$ & $168.33 \pm 40.30$ & $166.18 \pm 50.58$ & $156.76 \pm 50.23$ & 0.547 \\
\hline $\operatorname{ALT}(\mathrm{U} / \mathrm{L})$ & $216.91 \pm 222.43$ & $269.88 \pm 258.75$ & $165.86 \pm 178.09$ & 0.091 \\
\hline Bilirubin $(\mu \mathrm{mol} / \mathrm{L})$ & $16.06 \pm 11.06$ & $22.92 \pm 18.58$ & $23.21 \pm 23.11$ & 0.025 \\
\hline Albumin $(\mathrm{g} / \mathrm{L})$ & $40.25 \pm 4.27$ & $39.42 \pm 4.01$ & $39.05 \pm 4.91$ & 0.386 \\
\hline Creatinine (mmol/L) & $76.47 \pm 17.84$ & $73.36 \pm 15.63$ & $73.45 \pm 15.42$ & 0.853 \\
\hline PT (s) & $13.11 \pm 1.32$ & $13.45 \pm 2.13$ & $13.56 \pm 1.26$ & 0.430 \\
\hline HBV-DNA $\left(\log _{10} \mathrm{IU} / \mathrm{ml}\right)$ & $6.55 \pm 1.28$ & $6.69 \pm 1.09$ & $6.35 \pm 1.06$ & 0.462 \\
\hline $\mathrm{HBsAg}\left(\log _{10} \mathrm{IU} / \mathrm{mL}\right)$ & $3.95 \pm 0.93$ & $3.70 \pm 0.73$ & $3.19 \pm 0.92$ & 0.001 \\
\hline
\end{tabular}

HBsAg and higher levels of bilirubin, however, the mean values of HBV DNA, age and platelet count showed no significant differences among the three groups.

Correlation between CPA, HBsAg and HBV DNA

There was a modest correlation observed between CPA and serum HBsAg $(r=-0.306, p=0.001)$, serum HBsAg and HBV DNA $(r=0.322, p<0.001)$; but poor correlation between CPA and serum HBV DNA $(r=$ $-0.031, p=0.728)$ (Fig. 1).

To evaluate whether the level of HBsAg is independently associated with CPA, multivariable linear regression analyses were conducted to adjust for clinically important factors (Table 3). The association between HBsAg level and CPA remained significant in Model 1 (unadjusted) and Model 2 (adjusted with age, gender) (all standardized $\beta=-0.022 ; p=0.002$ ) and persisted with slight attenuation in $\beta$ value even after adjustment with PLT, Bilirubin and HBV DNA level (standardized $\beta=-0.022$ to $-0.021 ; p=0.004$ ). 
Table 3

Linear regression of $\mathrm{HBsAg}(\log 10 \mathrm{IU} / \mathrm{mL})$ on CPA in the 128 patients with advanced cirrhosis

\begin{tabular}{|lccc|}
\hline \multicolumn{1}{|l}{ B } & $95 \% \mathrm{Cl}$ & P \\
\hline HBsAg & & & \\
\hline Model 1 = unadjusted & -0.022 & $-0.035--0.008$ & 0.002 \\
\hline Model 2 = adjusted with age, gender & -0.022 & $-0.035--0.008$ & 0.002 \\
\hline Model 3 = Model 2 + PLT, Bilirubin and HBV DNA & -0.021 & $-0.035--0.007$ & 0.004 \\
\hline $\begin{array}{l}\text { HBsAg, hepatitis B surface antigen; CPA, collagen proportionate area; Cl, confidence interval; PLT, } \\
\text { platelets. }\end{array}$ & & \\
\hline
\end{tabular}

\section{Discussion}

Liver fibrosis and stage have always been confused in histological staging systems, staging liver disease is important in routine histopathological assessment while measurement of liver fibrosis is another process[13]. CPA as a continuous variable is a suitable histological measurement to assess the degree of fibrosis and substage cirrhosis, as an improvement of liver disease stage description. This is the first study evaluated the relationship between quantitative assessment of fibrosis on liver biopsies by measurement of the CPA and qHBsAg in treatment-naive HBeAg-positive patients with liver cirrhosis.

In this cohort, there was a modest correlation observed between serum HBsAg and HBV DNA, as well as an inverse correlation between CPA and serum HBsAg, but poor correlation between CPA and serum HBV DNA. Stronger correlation of HBsAg with HBV DNA in HBeAg positive patients has been previously described[4, 5, 17]. HBsAg circulates in a wide array of particulate forms: competent virions, spherical or a long filamentous form, corresponding to non-infectious sub-viral particles (SVPs)[18]. The SVPs can be found in great excess over competent virions in the serum of patients with chronically HBV infection (over 100,000 fold). Until now, two sources of HBsAg have been identified: covalently closed circular DNA (cccDNA) derived and integrated DNA derived. HBsAg produced from cccDNA generates all the mRNAs needed for HBV replication including SVPs, but integrated sequences can only provide SVPs since the complete genome is not present[3]. Currenttly, commercially available quantitative HBsAg assays are unable to differentiate the three HBsAg particles (whole virions, spheres and filaments). Different relationship between serum HBsAg, HBV DNA and CPA may represent differential regulation of expression and its molecular source of HBsAg and HBV DNA.

We found HBsAg level is independently associated with CPA in patients with liver cirrhosis. The mechanisms why increasingly fibrosis is associated with lower serum HBsAg in our cohort is unclear. Firstly, the presence of mutations within the pre-S/S region might impair virion secretion, impact HBV replication, or change the ability of HBsAg to bind to antibodies, thus result in decreased detectable levels of serum HBsAg[19]. Higher frequency of preS/S mutants may appear under selective pressure during 
immune clearance[20], patients with advanced liver disease had more frequent changes in the pre-S/S regions[21]. Both of these contribute to lower detectable HBsAg levels in patients with advance fibrosis. Secondly, the host immune system may activate and increasingly targets HBsAg production, or HBsAg is partially masked in immune complexes, without preventing the underlying fibrosis development. In addtion, an increasing CPA reflect a decreasing hepatic parenchyma cells'volume that might diminished the ability of the host for HBsAg production. Alternatively, HBsAg particles retention within hepatocyte but not secretion can aslo cause qHBsAg decline with increasing severity of fibrosis.

To our knowledge, our study is the first to associate an HBsAg level with liver fibrosis severity determined by CPA in patients with liver cirrhosis. Nonetheless, our study has a few limitations. In previous studies, older patients always have more severe liver fibrosis [22-24]. Interestingly, there is no significant correlation between age and liver fibrosis at multivariate analysis in our cohort. Our patients were relatively young (median age 29 years), this may due to a selection bias, as all patients underwent liver biopsy to diagnose significant fibrosis or cirrhosis (with clinical indications for liver biopsy), but these with clear clinical signs of liver cirrhosis were excluded at baseline. Thus one limitation of our study is a selection of a cohort with early cirrhosis. Secondly, although HBV genotypes B and C are the predominant HBV genotypes in China, HBV genotyping was not performed in our study. The role of qHBsAg in different genotypes is not fully described [25], future studies involving patients with different genotypes are required to validate our findings. Moreover, presence of mutations within the pre-S/S region might impair the HBsAg generation type and absolute values of HBsAg, pre-S/S region mutations were not evaluated in our study. Of note, high HBsAg level has been reported to be associated with long-term cirrhosis and hepatocellular carcinoma risk [22, 26-28], demonstrating that high HBsAg level was not always favorable in the process of HBV infection. Thus, further large, longitudinal trials enrolling patients in different phases of CHB are needed to uncover the potential mechanism of HBsAg in chronic HBV infection.

\section{Conclusions}

In conclusion, in our cohort with e antigen positive patients, serum HBsAg levels can predict liver fibrosis determined by CPA in liver cirrhosis.

\section{Abbreviations}

HBsAg, hepatitis B surface antigen

HBV, hepatitis B virus

CHB, chronic hepatitis B

ALT, alanine aminotransferase

DIA, digital image analysis 
CPA, collagen proportionate area

SVPs, sub-viral particles

cccDNA, covalently closed circularDNA

\section{Declarations}

\section{Ethics approval and consent to participate}

The protocols used in this retrospective study was reviewed and approved by the institutional review board of the first affiliated hospital of zhengzhou university. This is a retrospective study. The need for informed consent was waived by the Clinical Research Ethics Committee. The management and publication of patients' information in this study was strictly in accordance with the Declaration of Helsinki.

\section{Consent for publication}

Not applicable.

\section{Availability of data and materials}

All relevant data are within the paper. The data underlying this study are available and researchers may submit data requests to the the corresponding author on reasonable request.

\section{Competing interests}

All the authors declared that they have no competing interests.

\section{Funding}

The project supported by Youth Foundation of the first affiliated hospital of Zhengzhou university.

\section{Authors' contributions}


YR designed the study and determined the CPA by DIA. SQW designed the study and drafted the manuscript. SQ did statistical analysis. WCF, YJN and ZLF were involved in the review and revision of the original draft. All authors read and approved the final manuscript.

\section{Acknowledgements}

Not applicable.

\section{Authors' information}

Rui Yu, Email: yurui312@163.com

Qiangwei Shi, Email: shiqiangwei2007@126.com

Qian Sun, Email: sunqiande2008@163.com

Chunfeng Wang, Email: wchf15@163.com

Jianning Yao, Email: jianningyao@163.com

Lianfeng Zhang, Email: zhanglianfeng110@163.com

\section{References}

1. Blumberg BS, Alter HJ, Visnich S: A "New" Antigen in Leukemia Sera. Jama 1965, 191:541-546.

2. Nguyen $T$, Desmond $P$, Locarnini $S$ : The role of quantitative hepatitis $B$ serology in the natural history and management of chronic hepatitis B. Hepatology international 2009, 3(Suppl 1):5-15.

3. Cornberg M, Wong VW, Locarnini S, Brunetto M, Janssen HLA, Chan HL: The role of quantitative hepatitis B surface antigen revisited. Journal of hepatology 2017, 66(2):398-411.

4. Jaroszewicz J, Calle Serrano B, Wursthorn K, Deterding K, Schlue J, Raupach R, Flisiak R, Bock CT, Manns MP, Wedemeyer $\mathrm{H}$ et al: Hepatitis B surface antigen (HBsAg) levels in the natural history of hepatitis B virus (HBV)-infection: a European perspective. Journal of hepatology 2010, 52(4):514522.

5. Nguyen T, Thompson AJ, Bowden S, Croagh C, Bell S, Desmond PV, Levy M, Locarnini SA: Hepatitis B surface antigen levels during the natural history of chronic hepatitis B: a perspective on Asia. Journal of hepatology 2010, 52(4):508-513. 
6. Brunetto MR, Oliveri F, Colombatto P, Moriconi F, Ciccorossi P, Coco B, Romagnoli V, Cherubini B, Moscato G, Maina AM et al: Hepatitis B surface antigen serum levels help to distinguish active from inactive hepatitis B virus genotype D carriers. Gastroenterology 2010, 139(2):483-490.

7. Liaw YF: Clinical utility of hepatitis B surface antigen quantitation in patients with chronic hepatitis B: a review. Hepatology 2011, 53(6):2121-2129.

8. Martinot-Peignoux M, Carvalho-Filho R, Lapalus M, Netto-Cardoso AC, Lada O, Batrla R, Krause F, Asselah T, Marcellin P: Hepatitis B surface antigen serum level is associated with fibrosis severity in treatment-naive, e antigen-positive patients. Journal of hepatology 2013, 58(6):1089-1095.

9. Seto WK, Wong DK, Fung J, Ip PP, Yuen JC, Hung IF, Lai CL, Yuen MF: High hepatitis B surface antigen levels predict insignificant fibrosis in hepatitis $\mathrm{B}$ e antigen positive chronic hepatitis $\mathrm{B}$. PloS one 2012, 7(8):e43087.

10. Bedossa P, Poynard T: An algorithm for the grading of activity in chronic hepatitis C. The METAVIR Cooperative Study Group. Hepatology (Baltimore, Md) 1996, 24(2):289-293.

11. Ishak K, Baptista A, Bianchi L, Callea F, De Groote J, Gudat F, Denk H, Desmet V, Korb G, MacSween $\mathrm{RN}$ et al: Histological grading and staging of chronic hepatitis. Journal of hepatology 1995 , 22(6):696-699.

12. Desmet VJ, Gerber M, Hoofnagle JH, Manns M, Scheuer PJ: Classification of chronic hepatitis: diagnosis, grading and staging. Hepatology 1994, 19(6):1513-1520.

13. Germani G, Burroughs AK, Dhillon AP: The relationship between liver disease stage and liver fibrosis: a tangled web. Histopathology 2010, 57(6):773-784.

14. Standish RA, Cholongitas E, Dhillon A, Burroughs AK, Dhillon AP: An appraisal of the histopathological assessment of liver fibrosis. Gut 2006, 55(4):569-578.

15. Jimenez W, Pares A, Caballeria J, Heredia D, Bruguera M, Torres M, Rojkind M, Rodes J: Measurement of fibrosis in needle liver biopsies: evaluation of a colorimetric method. Hepatology 1985, 5(5):815818.

16. Calvaruso V, Dhillon AP, Tsochatzis E, Manousou P, Grillo F, Germani G, Patch D, O'Beirne J, Burroughs AK: Liver collagen proportionate area predicts decompensation in patients with recurrent hepatitis $\mathrm{C}$ virus cirrhosis after liver transplantation. Journal of gastroenterology and hepatology 2012, 27(7):1227-1232.

17. Thompson AJ, Nguyen T, Iser D, Ayres A, Jackson K, Littlejohn M, Slavin J, Bowden S, Gane EJ, Abbott $W$ et al: Serum hepatitis $B$ surface antigen and hepatitis B e antigen titers: disease phase influences correlation with viral load and intrahepatic hepatitis B virus markers. Hepatology 2010, 51(6):1933-1944.

18. Brunetto MR: A new role for an old marker, HBsAg. Journal of hepatology 2010, 52(4):475-477.

19. Xiang KH, Michailidis E, Ding H, Peng YQ, Su MZ, Li Y, Liu XE, Dao Thi VL, Wu XF, Schneider WM et al: Effects of amino acid substitutions in hepatitis $B$ virus surface protein on virion secretion, antigenicity, HBsAg and viral DNA. Journal of hepatology 2017, 66(2):288-296. 
20. Pollicino T, Amaddeo G, Restuccia A, Raffa G, Alibrandi A, Cutroneo G, Favaloro A, Maimone S, Squadrito G, Raimondo G: Impact of hepatitis B virus (HBV) preS/S genomic variability on HBV surface antigen and HBV DNA serum levels. Hepatology 2012, 56(2):434-443.

21. Pollicino T, Cacciola I, Saffioti F, Raimondo G: Hepatitis B virus PreS/S gene variants: pathobiology and clinical implications. Journal of hepatology 2014, 61(2):408-417.

22. Lee MH, Yang HI, Liu J, Batrla-Utermann R, Jen CL, lloeje UH, Lu SN, You SL, Wang LY, Chen CJ et al: Prediction models of long-term cirrhosis and hepatocellular carcinoma risk in chronic hepatitis $\mathrm{B}$ patients: risk scores integrating host and virus profiles. Hepatology 2013, 58(2):546-554.

23. Tan $Y$, Ye Y, Zhou X, Chen L, Wen D: Age as a predictor of significant fibrosis features in HBeAgnegative chronic hepatitis $B$ virus infection with persistently normal alanine aminotransferase. PloS one 2015, 10(4): $\mathrm{e} 0123452$.

24. Chen CJ, Yang HI, Su J, Jen CL, You SL, Lu SN, Huang GT, lloeje UH, Group R-HS: Risk of hepatocellular carcinoma across a biological gradient of serum hepatitis B virus DNA level. JAMA : the journal of the American Medical Association 2006, 295(1):65-73.

25. Sozzi V, Walsh R, Littlejohn M, Colledge D, Jackson K, Warner N, Yuen L, Locarnini SA, Revill PA: In Vitro Studies Show that Sequence Variability Contributes to Marked Variation in Hepatitis B Virus Replication, Protein Expression, and Function Observed across Genotypes. Journal of virology 2016, 90(22):10054-10064.

26. Tseng TC, Liu CJ, Yang HC, Su TH, Wang CC, Chen CL, Kuo SF, Liu CH, Chen PJ, Chen DS et al: High levels of hepatitis B surface antigen increase risk of hepatocellular carcinoma in patients with low HBV load. Gastroenterology 2012, 142(5):1140-1149 e1143; quiz e1113-1144.

27. Qu LS, Liu JX, Zhang HF, Zhu J, Lu CH: Effect of serum hepatitis B surface antigen levels on predicting the clinical outcomes of chronic hepatitis B infection: A meta-analysis. Hepatology research : the official journal of the Japan Society of Hepatology 2015, 45(9):1004-1013.

28. Huang G, Lau WY, Zhou WP, Shen F, Pan ZY, Yuan SX, Wu MC: Prediction of Hepatocellular Carcinoma Recurrence in Patients With Low Hepatitis B Virus DNA Levels and High Preoperative Hepatitis B Surface Antigen Levels. JAMA surgery 2014, 149(6):519-527.

\section{Figures}



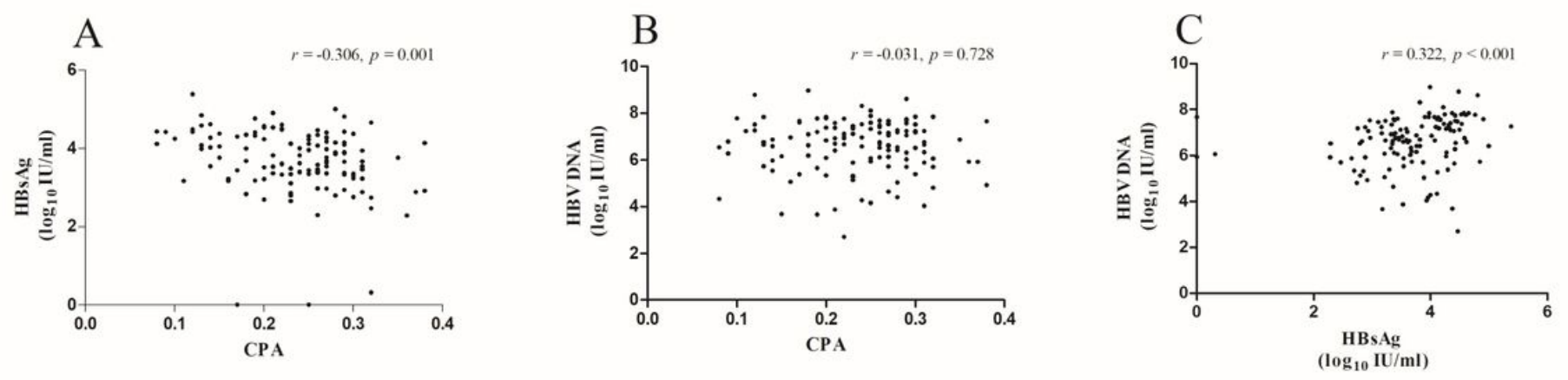

\section{Figure 1}

A modest correlation observed between collagen proportionate area and serum $\mathrm{HBsAg}$ (a), serum $\mathrm{HBsAg}$ and HBV DNA (b); but poor correlation between collagen proportionate area and serum HBV DNA (c). Abbreviations: CPA, collagen proportionate area; HBsAg, hepatitis $B$ surface antigen 